chúng tôi là 1 tháng khi tình trạng bệnh nhân đã ổn định hơn. Điều này được phản ánh thông qua điểm Barthel trung bình của người bệnh là 88,76 $\pm 15,8$ trong đó chủ yếu là nhóm người bệnh không phụ thuộc (68 người chiếm $60,2 \%$ ), cao hơn nhiều so với 47,8 \pm 19,9 điểm trong công bố của Nguyễn Thành Chung [7].

\section{KẾT LUẦN}

44,2\% người chăm sóc không có gánh nặng. $55,8 \%$ còn lại có gánh nặng chăm sóc từ vừa phải đến từ trung bình. Không có trường hợp nào cảm thấy gánh nặng ở mức nghiêm trọng. Không có sự khác biệt về gánh nặng chăm sóc giữa người chăm sóc là nam hay nữ $(p=0,63)$, tình trạng hôn nhân $(p=0,43)$, trình độ học vấn $(p=0,06)$

\section{TÀI LIỆ THAM KHẢO}

1. Carod-Artal, F.J., et al. (2009), Burden and perceived health status among caregivers of stroke patients. Cerebrovasc Dis, 28(5) p. 472-80.

2. Kazemi, A., et al. (2020), Caregiver Burden and Coping Strategies in Caregivers of Elderly Patients with Stroke.

3. Lu, L., et al. (2009), Zarit Caregiver Burden Interview: Development, reliability and validity of the Chinese version. Psychiatry and Clinical Neurosciences, 63(6) p. 730-734.

4. Mandowara, B., et al. (2020), Burden Faced by Caregivers of Stroke Patients Who Attend Ruralbased Medical Teaching Hospital in Western India. Annals of Indian Academy of Neurology. 23(1): p. 38-43.

5. Choi-Kwon, S., et al. (2005), Factors affecting the burden on caregivers of stroke survivors in South Korea. Arch Phys Med Rehabil, 86(5) p. 1043-8.

6. Nguyễn Bích Ngọc (2013), Đánh giá gánh nặng của người chăm sóc trong bệnh alzheimer. Tạp chí Y hoc dư phòng, Tâp XXIII, số 5

7. Nguyê̂n Thành Chung (2016), Nghiên cứu gánh năng chăm sóc người bênh sau đôt quy não tai gia đình ở tỉnh Nam Đinh năm 2016. Luân văn thac sĩ điều dưỡng.

\title{
KẾT QUẢ HÓA XA TRI TIỀN PHẪU UNG THƯ THỰC QUẢN 1/3 GIŨ̃A- DƯỚI GIAI ĐOẠN II, III TẠI BỆNH VIỆN TRUNG ƯƠNG QUÂN ĐộI 108
}

\section{TÓM TẮT.}

Muc tiêu: Mô tả môt số đăc điểm lâm sàng, cân lâm sàng của bệnh nhân ung thư thực quản $1 / 3$ giứadưới giai đoan İI, III tai bênh viện Trung ương Quân đội 108 được hóa xạ trị tiền phẫu và đánh giá kết quả điêu trị của nhóm bệnh nhân trên. Đối tượng và phương pháp: Nghiền cứu mô tả hồi cứu kết hợp tiến cứu trên 44 bệnh nhân ung thư thực quản $1 / 3$ giữa - $1 / 3$ dưới giai đoạn II-III điều trị hóa xa trị tiên phẫu với phác đồ hóa chất Paclitaxel/Carboplatin kết hợp liều xạ trị 41,4Gy/23Fx và phâuu thuật. Kết quả: Tuổi trung bình là 55 , tỷ lệ nam là $97,7 \%$. Triệu chứng chủ yếu là nuốt nghẹn $81,8 \%$, sút cân găp ở $27 / 44$ $(61,2 \%)$, chiều dài trung bình của u là $6 \pm 0,25 \mathrm{~cm}$. Đáp ứng hoàn toàn trên cận lâm sàng tương ứng là $38,6 \%$. Đáp ứng hoàn toàn trên giải phâuu bệnh là $43,2 \%$ (pTON0). Các độc tính chủ yếu đồ 1-2 bao gồm mệt mỏi, viêm niêm mạc thực quản, hạ bạch cầu. Kết luần: hóa xa trị tiền phấu là phương pháp điều trị có hiệu quả cho ung thư thực quản $1 / 3$ giữa- dưới giai đoạn II-III với tác dụng không mong muốn có thể chẩp nhân được.

Tư khóa: Hóa xạ trị tiền phẫu, ung thư thực quản.

${ }^{1}$ Bệnh viện Trung ương quân đội 108

${ }^{2}$ Bộ môn Ung thur, Trường Đại hoc Y Hà Nội

Chịu trách nhiệm chính: Trịnh Lế Huy

Email: trinhlehuy@hmu.edu.vn

Ngày nhận bài: 16.6.2021

Ngày phản biên khoa hoc: 13.8.2021

Ngày duyệt bài: 18.8.2021
Nguyễn Thị Hà1, Trịnh Lê Huy ${ }^{2}$

\section{SUMMARY \\ RESULTS OF NEOADJUVANT CONCURRENT CHEMORADIOTHERAPY IN STAGE II-III \\ MIDDLE-LOWER THIRD ESOPHAGEAL CANCER AT 108 CENTRAL MILITARY HOSPITAL}

Objectives:To assess the treatment results of neoadjuvant chemoradiation in the middle and lower thirds, stage II, III esophageal cancer patients at the 108 Military Central Hospital. Subject and method:A retrospective and prospective descriptive study with 44 stage II-III esophageal cancer patientsunderwent preoperative, concurrent chemotherapy with paclitaxel/carboplatin and radiation with a dose of 41.4Gy/23fx followed by surgery. Results: The means age was 55 years old, the percentage of malewas $97,7 \%$. The dysphagia rate was 81,8 , weight loss was found in $27 / 44(61,2 \%)$, the mean length of tumor is $6 \pm 0.25 \mathrm{~cm}$. The subclinical complete responses were $38.6 \%$. The pathology complete response was $43.2 \%$ (PTONO) and RO resection was achieved for 41 patients (93.2\%). Side effects fatigue, esophageal mucositis, and leukopenia, most of which were in grade 1-2.Conclusions:Preoperative chemoradiation in an effective treatment for stgage IIIII esophageal cancer patients with acceptable side effects, complications, and surgical complications.

Keywords: Esophageal cancer, preoperative chemoradiotherapy. 


\section{I. ĐẠT VẤN ĐỀ}

Ung thư thực quản (UTTQ) là bệnh lý ác tính nằm trong nhóm các bệnh ung thư có tỷ lệ mắc mới và về tỷ lệ tử vong cao. Theo số liệu thống kê Globocan 2020, ước tính có khoảng 604127 ca mắc mới và 544076 ca tử vong trong năm 2020[1]. Riêng ở Việt Nam, năm 2020 có khoảng 3281 trường hợp mắc mới, nằm trong 15 nhóm bệnh ung thư hay gặp nhất. Điều trị ung thư thực quản là điều trị đa mô. Hóa xạ trị tân bổ trợ kết hợp phẫu thuât triêt căn là điều trị chuẩn cho UTTQ 1/3 giữa- dưới. Tại bệnh viên Trung ương Quân đội 108 hóa xạ trị tiền phẫu UTTQ đã ứng dụng từ năm 2015 tuy nhiên chưa có nghiên cứu chính thức nào đánh giá hiệu quả của phác đồ hóa xạ trị này, vì vậy chúng tôi tiến hành nghiên cứu này với mục tiêu: Mô tả một số đặc điểm lâm sàng của bệnh nhân UTTQ 1/3 giữa- dưới giai đoạn II-III tại bệnh viện 108 và đánh giá kêt quả điều trị hóa xạ trị tiền phẫu trên những bệnh nhân này.

\section{II. ĐỐI TƯƠNG VÀ PHƯƠNG PHÁP NGHIÊN CỨU}

1. Đối tượng nghiên cứu. Gồm 44 bệnh nhân UTTQ đoạn II-III điêu trị hóa xạ trị tiền phẫu- phẫu thuật tại Bệnh viện Trung Ương Quân Đội 108 từ tháng 12/2015 đến tháng $12 / 2020$.

\section{* Tiêu chuấn lứa chọn:}

- Bệnh nhân tuổi: 18-70 tuổi được chẩn đoán UTTQ vị trí $1 / 3$ giữa- dưới giai đoạn II-III. Toàn trạng $E C O G<2$. Chẩn đoán mô bệnh học là ung thư biểu mô và có đây đủ hồ sơ theo dõi, được giải thích đây đủ và tự nguyện đồng ý tham gia nghiên cứu.

* Tiêu chuâin loại trừ: Các bệnh nhân mất thông tin theo dõi, có bệnh lý kết hợp nặng hoặc có ung thư thứ 2 trong vòng 5 năm.

\section{Phương pháp nghiên cứu}

* Thiết kế nghiên cứu: mô tả hồi cứu kết hợp tiến cứu

* Cõ mẫu và chọn mẫu: Lâyy thuận tiện (tất cả BN đủ tiêu chuẩn trên được điều trị từ tháng 10/ 2015 đến 12/2020).

* Các biến số nghiên cứu:

- Đặc điểm lâm sàng, cận lâm sàng: tuổi, tiên sử, triệu chứng cơ năng, giai đoạn bệnh, vị trí u.

- Đánh giá đáp ứng điều trị sau khi kết thúc hóa xạ trị 04- 06 tuân theo RESIST1.1. Đánh giá đáp ứng trên giải phẫu bệnh sau phẫu thuật.

- Đánh giá tác dụng không mong muốn trong quá trình điêu trị theo CTCAE [4], tai biến và biến chứng của phẫu thuật.

* Xü Iý sốliệu: bằng phân mềm SPSS 22.0.

\section{KẾT QUẢ NGHIÊN CỨU}

\section{1. Đặc điểm lâm sàng và cận lâm sàng} UTTQ. Kết quả nghiên cứu cho thấy tuổi trung bình là 55 tuổi, trong đó nam chiếm 97,7\%, giải phẫu bệnh trước điều trị là 100 \%ung thư biểu mô vảy. Các yếu tố nguy cơ UTTQ bao gồm rượu và thuốc lá chiếm 95,4\%, tỷ lệ bệnh nhân tiền sử sử dụng đơn thuân rượu hoặc thuốc lá chỉ chiếm có 2,3\%.

Các triệu chứng lâm sàng chủ yếu của bệnh nhân là nuốt nghẹn, $81,8 \%$ bệnh nhân có triệu chứng liên quan đến nuốt nghẹn chủ yếu là độ 1-2; chỉ có 3 trường hợp nuốt nghẹn độ 4 . Chủ yếu bệnh nhân sút < 10\% trọng lượng cơ thể chiếm 38,6\%.

Đánh giá giai đoạn bệnh 84,1\% bệnh nhân ở giai đoạn III và 15,9 \% bệnh nhân ở giai đoạn II. Chiêu dài trung bình của khối u là $6 \pm 0,25 \mathrm{~cm}$.

Bảng 1: Đăc điểm lâm sàng và cận lâm sàng

\begin{tabular}{|c|c|c|c|}
\hline Thông tin & $\mathbf{N}(\%)$ & Thông tin & $\mathbf{n ~ ( \% )}$ \\
\hline Tuôói & $55 \pm 8(39-70)$ & GPB: SCC & $44 / 44(100 \%)$ \\
\hline & & Sút cân: Không & $17 / 44(38,6 \%)$ \\
Giới: Nam & $43 / 44(97,7 \%)$ & $\leq 5 \%$ & $10 / 44(22,7 \%)$ \\
Nữ & $1 / 44(2,3 \%)$ & $5-10 \%$ & $14 / 44(31,8 \%)$ \\
& & $\geq 10 \%$ & $3 / 44(6,8 \%)$ \\
\hline Nuốt nghẹn: Độ 1 & $24 / 44(54,5 \%)$ & Tiền sử: Không & $1 / 44(2,3 \%)$ \\
Độ 2 & $12 / 44(27,3 \%)$ & Rươu & $1 / 44(2,3 \%)$ \\
Độ 3 & $3 / 44(6,8 \%)$ & Thuốc lá & $0 / 44(0 \%)$ \\
Độ̂ 4 & $3 / 44(6,8 \%)$ & Rượu + thuốc lá & $42 / 44(95,4 \%)$ \\
Không nuốt nghẹn & $2 / 44(4,5 \%)$ & Giai đoạn hạch: N0 & $4 / 44(9,1 \%)$ \\
\hline Giai đoạn u: T2 & $5 / 44(11,4 \%)$ & N1 & $24 / 44(54,5 \%)$ \\
T3 & $39 / 44(88,6 \%)$ & N2 & $16 / 44(36,4 \%)$ \\
\hline Vị trí: $1 / 3$ giữa & $21 / 44(47,7 \%)$ & Giai đoạn TNM: II & $7 / 44(15,9 \%)$ \\
1/3 dưới & $21 / 44(52,3 \%)$ & III & $37 / 44(84,1 \%)$ \\
\hline
\end{tabular}


2. Kết quả điêuu trị. Sau điêu trị hóa xạ trị 04- 06 tuần, có $79,6 \%$ bệnh nhân không còn và thuyên giảm triệu chứng nuốt nghẹn. Trên nội soi, tỷ lệ đáp ứng một phần là $26 / 44(59,1 \%)$ và đáp ứng hoàn toàn là $7 / 44(15,1 \%)$. Đánh giá sau phẩu thuật: đáp ứng hoàn của u trên giải phẫu bệnh là 21/44 (47,7\%). Đáp ứng hoàn toàn cả u và hạch pTONO là 19/44 (43,2\%). Số hạch trung bình vét được là 17 hạch. Tỷ lệ đạt diện cắt R0 là $93,2 \%$. Tỷ lệ đáp ứng hoàn toàn ở mỗi nhóm theo từng giai đoạn bệnh, kỹ thuật xạ trị, liều hóa chất có sự khác nhau, tuy nhiên sự khác biệt không có ý nghĩa thống kê $(p>0,05)$.

Tác dụng không mong muốn hầu hết đều ở độ 1,2; chỉ có 2 tường hợp gặp viêm thực quản ở đổ $3(4,5 \%)$. Tác dụng không mong muốn trên hể huyết học chủ yểu là giảm bạch cầu độ 1,2 , có $3 / 44$ ca giảm $B C$ độ 3 , giảm bạch cầu hạt độ 3-4 gặp ở 4,5\%; Giảm tiểu cầu, thiếu máu gặp ít hơn và chủ yếu là độ 1 . Tăng men gan là $9 / 44$ chiếm $20,5 \%$ chủ yểu độ 1 . Không gặp trường hợp nào tăng creatinin.

Các tai biến, biến chứng trong quá trình phẫu thuật bao gồm viêm phổi, rò miệng nối gặp ở $1 / 44(2,3 \%)$, hẹp miệng nối trong 30 ngày đầu hậu phẩu gặp ở 2/44 (4,6\%). Có 01/44 (2,3\%) trường hợp suy hô hấp và tử vong trong thời gian hậu phẫu.

\section{BÀN LUÂN}

1. Đặc điểm lâm sàng, cận lâm sàng. Qua nghiên cứu 44 bệnh nhân ung thư thực quản hóa xạ trị tiền phẫu và phẫu thuật cho thấy tuổi trung bình. $55 \pm 8$ (39-70), nhóm tuổi gặp cao nhất là 40-59 tuổi. Kết quả của chúng tôi tương tự với các tác giả trong nước như Pham Đức Huẩn và cs [3] với tuổi trung bình là 53 (4370 tuổi), của Nguyễn Đức Lợi là 38-80 tuổi, hay gặp nhất ở nhóm 40-59 tuổi [4]; nghiên cứu của P.van Hagen là 60 (36-79) [5]. Ung thư thực quản cũng gặp chủ yếu ở nam giới chiếm $97,7 \%$ tương tự như nghiên cứu khác là 96,9\%[3]. Các yếu tố nguy cơ UTTQ bao gồm rượu và thuốc lá gặp ở 42/44 bệnh nhân. Các nghiên cứu đã chứng minh mối liên quan mạnh mẽ giữa hút thuốc lá, rượu và và UTTQ [6].

Trong nghiên cứu của chúng tôi, triệu chứng chủ yếu của bệnh nhân là nuốt nghẹn $81,8 \%$ và chủ yếu là độ $1-2$, tương tự như một số nghiên cứu khác như của Nguyển Xuân Hòa là $77,67 \%$ [7]. Triệu chứng sút cân chủ yêu dưới $10 \%$ trọng lượng cơ thể 38,6\%, theo Nguyễn Đức Lợi tỷ lệ sút cân là $35,6 \%[4]$. Về vị trí giải phẫu u thực quản $1 / 3$ giữa và dưới tương tư là $47,7 \%$ và $52,3 \%$, tương tự như của Nguyến Xuân Hòa là
$44 \%$ và $56 \%$ [7]; Khối u nguyên phát có chiều dài trung bình là $\pm 0,25 \mathrm{~cm}$, nghiên cứu của P.van Hagen là $4,0 \mathrm{~cm}$ [5]

2. Kết quả phác đồ điêu trị. Các nghiên cứu hóa xạ trị tiên phẫu ung thư thực quản sử dụng liều xạ 41,4Gy/23 Fx với phác đồ hóa chất thường sử dụng là Paclitaxel/ Carboplatin nhằm làm tăng tính nhạy cảm của tế bào ung thư với tia xạ và tiêu diệt các tế bào vi di căn [8].

Đáp ứng hoàn toàn trên nội soi và CLVT tương ứng là $38,6 \%$ và $22,7 \%$ tương tự như các nghiên cứu khác là 18, 9\%[9]. Đáp ứng hoàn toàn trên giải phẫu bệnh sau phấu thuật là $43,2 \%$. Trong nghiên cứu CROSS so sánh giữa 2 nhóm hóa xạ trị tiền phẫu kết hợp phẫu thuật và phẫu thuật đơn thuần cho kết quả tỷ lệ đáp ứng hoàn toàn giải phẫu bệnh (pCR) là $29 \%$, nếu xét riêng nhóm ung thư biểu mô tuyến (AC) là $23 \%$, ung thư biểu mô vảy (SCC) là $49 \%$ $(p=0,008)[5]$, trong nghiên cứu của chúng tôi $100 \%$ là ung thư biểu mô vảy vì vậy kết quả tương đương với nghiên cứu này.Số hạch vét được trung bình là 17 hạch tương đưởng với trong nghiên cứu CROSS, số hach vét được ở nhóm có hóa xạ trị là 15 và nhóm phẫu thuật đơn thuần là 18 [5].

Qua phân tích mối tương quan giữa tỉ lệ đáp ứng và một số yếu tố khác như giai đoạn bệnh, kỹ thuật xạ trị liều hóa chất, chúng tôi nhận thấy ít nhiều có sự khác nhau về tî lệ đáp ứng. Tuy nhiên sự khác biệt không có ý nghĩa thống kê với $p>0,05$. Có thể lý giải vì nghiên cứu của chúng tôi mẫu còn thấp, cần có những nghiên cứu lớn hơn để đánh giá về vấn đề này.

\section{Các tác dụng không mong muốn}

Các tác dụng không mong muốn viêm thực quản, viêm da, sút cân, buồn nôn, giảm bạch cầu, thiếu máu, giảm tiểu cầu chủ yếu độ 1,2 ; có 4,5\%- 6,8\% độ 3 tương tự như một số nghiên cứu khác [5], [9]. Kết quả của chúng tôi thấp hơn một số nghiên cứu khác cùng liều xạ và phác đồ hóa chất với viêm thực quản độ 3 là $7,5 \%$, giảm bạch cầu độ 4 gặp ở 23,5\%[9].

Tai biến, biến chứng trong nghiên cứu của chúng tôi viêm phổi và rò miệng nối $2,3 \%$, hẹp miệng nối trong 30 ngày đầu hậu phẩu gặp là $4,6 \%$ và có $01 / 44(2,3 \%)$ trường hợp suy hô hấp và tử vong trong thời gian hậu phẩu, $4,6 \%$ hẹp miệng nối trong vòng 30 ngày sau phấu thuật, tương đương so với các nghiên cứu khác như thử nghiệm CROSS, tuy nhiên thử nghiệm cũng cho thây không có sự khác biệt giữa 2 nhóm hóa xạ tri tiên phẫu và phấu thuật so với phẫu thuật đợn thuân[5]. 


\section{KẾT LUÂNN}

Với bênh nhân UTTQ giai đoan II, III vị trí $1 / 3$ giữa- dưới thường gặp ở nam giới có tiền sử liên quan đến thuốc lá và rượu. Triệu chứng thường gặp là nuốt nghẹn $81,8 \%$, sút cân $61,2 \%$. Phác đồ hóa xạ trị tiền phấu 41,4Gy/ 23Fx, hóa trị với paclitaxel, carboplatin mang lại hiệu quả cao với đáp ứng hoàn toàn, cận lâm sàng tương ứng là $38,6 \%$ và giải phẫu bệnh là $43,2 \%$ với các tác dụng không mong muốn, tai biến, biến chứng phẫu thuât có thể chấp nhân được.

Để đánh giá đây đủ hơn hiệu quả của phác đồ hóa xạ trị tiên phẫu cân số lượng bệnh nhân lớn hơn, cũng như thời gian theo dõi dài hơn, đánh giá thời gian sống thêm cũng như các biến chứng, tác dụng không mong muốn muốn.

\section{TÀl LIẸU THAM KHẢO}

1. Sung H., Ferlay J., Siegel R.L. và cộng sự. (2021). Global Cancer Statistics 2020: GLOBOCANN Estimates of Incidence and Mortality Worldwide for 36 Cancers in 185 Countries. CA Cancer J Clin, 71(3), 209-249.

2. (2017). Common Terminology Criteria for Adverse Events (CTCAE). 155.
3. Pham Đức Huấn (2003), Nghiên cứu điêu trị phẩu thuật ung thư thực quản, Luận án tiến sĩ y học, Trường Đại học Y Hà Nội.

4. Nguyến Đức Lợi (2015), Đánh giá hiệu quả phác đồ hoá xạ trị đồng thời và một số yếu tố tiên lượng ung thư biểu mô vẩy thực quản giai đoạn III,IV, Luân án tiến sĩ y hoc, Trường Đai hoc Y Hà Nổi.

5. van Hagen P., Hulshof M.C.C.M., van Lanschot J.J.B. và cộng sự. (2012). Preoperative Chemoradiotherapy for Esophageal or Junctional Cancer. N Engl J Med, 366(22), 2074-2084.

6. Cook M.B., Kamangar F., Whiteman D.C. và cộng sự. (2010). Cigarette smoking and adenocarcinomas of the esophagus and esophagogastric junction: a pooled analysis from the international BEACON consortium. J Natl Cancer Inst, 102(17), 1344-1353.

7. Nguyễn Xuân Hòa (2018), Nghiên cứu úng dung phẫu thuât nôi soi cắt thực quản và nao vét hạcch rộng hai vùng (ngực- bưng) trong điều trị ung thư thực quản., Luận án tiến sĩ y học, Trường Đai hoc Y Hà Nội, Hà Nối.

8. Choy H. (2000). Combining taxanes with radiation for solid tumors. Int J Cancer, 90(3), 113-127.

9. van Meerten $E_{\text {., }}$ Muller K., Tilanus H.W. và cộng sứ. (2006). Neoadjuvant concurrent chemoradiation with weekly paclitaxel and carboplatin for patients with oesophageal cancer: a phase II study. Br J Cancer, 94(10), 1389-1394.

\section{ĐẶC ĐIỂM LÂM SÀNG, CÂN LÂM SÀNG NẤM PHỔI XÂM LẤN ĐIỀU TRI! TẠI TRUNG TẦM HÔ HẤP BỆNH VIỆN BACH MAI}

\section{TÓM TẮT}

Mục tiêu: Mô tả đặc điểm lâm sàng, cận lâm sàng của các bênh nhân nhiễm nấm phổi xấm lấn điều trị tại trung tẩm Hô Hấp bệnh viện Bạch Mai. Đối tượng và phương pháp nghiên cứu: Nghiên cứu mô tả hồi cứu, tiến cứu trên 41 bệnh nhân nhiễm nấm phổi xâm lấn, điều tri tai Trung tẩm Hô Hấp bênh viên Bach Mai thời gian từ 01/2019-06/2021. Kết quả: Khoảng 2/3 bệnh nhân nhiếm nấm xâm lấn là nam giới, nhóm trên 60 tuổi chiếm 53,7\%. COPD và Hen phế quản $(31,7 \%)$, đái tháo đường týp $2(24,4 \%)$ là những bệnh đồng mắc thường gặp. Lý do nhập viện rất đa dạng nhưng phổ biến làho có đờm $(63,4 \%)$, khó thở $(51,2 \%)$, mệt $(36,6 \%)$, sốt $(31,7 \%)$. Trên xét nghiệm vi sinh chủng nấm thường gặp nhất là Aspergilus fumigatus $(65,9 \%)$. Kết luậân: Các dấu hiệu lâm sàng và cận lâm sàng của nhiếm nấm xâm lấn đa dạng,

\footnotetext{
${ }^{1}$ Bệnh viện Hữu Nghị Việt Tiệp Hải Phòng

${ }^{2}$ Trường Đại học Y Hà nọi

${ }^{3}$ Bênh viên Bach Mai

Chịu trách nhiệm chính: Vũ Thị Nhinh

Email: vunhinh.yhp@gmail.com

Ngày nhận bài: 21.6.2021

Ngày phản biên khoa hoc: 19.8.2021

Ngày duyệt bài: 25.8.2021
}

\section{Vũ Thị Nhinh'1, Vũ Văn Giáp ${ }^{2,3}$}

không đặc hiệu, cân phải nghĩ tới nấm ở những bệnh nhân có yếu tố cơ địa có triệu chứng hô hấp dai dẳng không cải thiện với các biện pháp điều trị thông thường. lâm sàng

Tư khóa: Nhiễm nấm phổi xâm lấn, lâm sàng, cận

\section{SUMMARY \\ CLINICAL, PARACLINICAL FEATURES OF PATIENTS WITH INVASIVE PULMONARY FUNGAL INFECTION}

Objective: To describe the clinical and paraclinical characteristics of patients with invasive pulmonary fungal infection. Population and Method: Retrospective, Prospective descriptive study on 41 patients with invasive pulmonary fungal infection treated at the Respiratory Center of BachMai Hospital in VietNam from January 2019 to 06/2021 Results: Approximately $2 / 3$ patients with invasive fungal infection were male, the group of patients over 60 years was $53,7 \%$. COPD and Asthma (31,7\%), type 2 diabetes $(24,4 \%)$ were the most frequent cormobidities. The very multifaceted reason for entry: productive cough $(63,4 \%)$, dyspnea $(51,2 \%)$, fatigue $(36,6 \%)$, fever $(31,7 \%)$. On the test ofmicrobiologie the most common fungal species is Aspergilus fumigatus $(65,9 \%)$. Conclusion: This study presented the clinical and paraclinical signs of invasive 